\title{
Book report \\ Procedures, Techniques, and Minimally Invasive Monitoring in Intensive Care Medicine, Fourth Edition
}

\author{
Andrew Rhodes
}

Department of Intensive Care Medicine, St George's Hospital, London, SW17 0QT

Corresponding author: Andrew Rhodes, andyr@sgul.ac.uk

Published: 21 December 2007

Critical Care 2007, 11:316 (doi:10.1186/cc6201)

This article is online at http://ccforum.com/content/11/6/316

(c) 2007 BioMed Central Ltd

Richard S Irwin, James M Rippe, Alan Lisbon, Stephen O Heard: Procedures, Techniques, and Minimally Invasive Monitoring in Intensive Care Medicine, $4^{\text {th }}$ Ed. ISBN: 078177862X Lippincott Williams \& Wilkins. 375 pages.

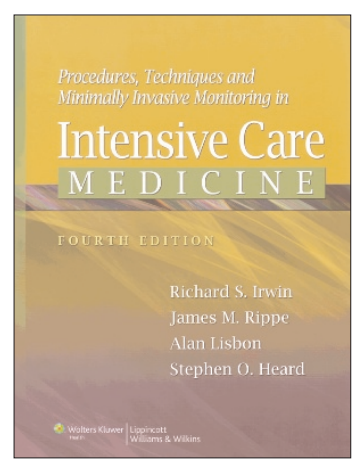

This is the fourth edition of a well-known textbook focusing on the procedures and techniques that are fundamental to the practice of Intensive Care Medicine. New to this edition is a separate section describing in seven chapters the techniques of minimally invasive monitoring modalities. Every chapter has undergone a thorough update that provides a modern and 'state of the art' understanding in all these areas. This book is meant to sit alongside the editors' other more comprehensive textbook on critical care medicine - Irwin and Rippe's Intensive Care Medicine (sixth edition).

The book is split into two sections. The first section covers procedures and techniques. These range from airway management through to more complex scenarios such as dialysis or gastrointestinal endoscopy. The second section details the techniques of minimally invasive monitoring. This is the new section for this book and is an up-to-date overview of monitoring modalities for all organ systems. The topics covered in this book should provide the reader with a comprehensive overview of all the procedures and techniques necessary for certification in critical care medicine, or indeed for any clinician training in another allied specialty that encompasses care of an acutely ill patient.

Each chapter consists of an overview of the techniques. There is a description of the anatomy, physiology and techniques involved, so that the reader can understand what the procedure entails. This is enhanced by a large number of line diagrams and clinical photographs and images that better explain the necessary details. Each chapter also contains a section detailing the available evidence behind the procedures, a discussion of the indications, contra-indications and limitations of each procedure and an invaluable source of references for further reading.
This book is sold with a soft cover. With 375 pages and a large-scale page format, it will be too large to fit into a doctor's pocket. Although large, however, it is not nearly as big as its allied textbook. This book is not something to be carried around. Its place will be to sit on the desk of an Intensive Care Unit or other appropriate ward setting. It will be read by the doctor learning and performing the tasks as detailed above. As such the excellent use of graphics and description of relevant anatomy will be of great use. I can see my trainees consulting this book for a long time to come!

\section{Competing interests}

AR has received lecture fees from both LiDCO and Edwards Lifesciences. 